[3] Johnson CJ, Reilly KM, Murray KM. Etanercept in juvenile rheumatoid arthritis. Annals of Pharmacotherapy 2001;35:464-71.

Disclosure of Interests: None declared

DOI: 10.1136/annrheumdis-2019-eular.7316

\section{AB1372-HPR THE INVESTIGATION OF THE RELATIONSHIP BETWEEN PSYCHOSOCIAL STATUS OF CHILDREN WITH JIA AND PARENTS}

Aykut Özçadırcı ${ }^{1}$, Aybüke Seven ${ }^{1}$, Gamze Arın ${ }^{1}$, Yasemin Özel Aslıyüce ${ }^{1}$, Fatma Birgül Kumbaroğlu' ${ }^{1}$, Nur Banu Karaca ${ }^{1}$, Selcan Demir ${ }^{2}$, Yelda Bilginer ${ }^{2}$, Edibe Ünal ${ }^{1}$, Seza Özen ${ }^{2} .{ }^{1}$ Hacettepe University Faculty of Physical Therapy and Rehabilitation, Ankara, Turkey, ${ }^{2}$ Hacettepe Universiy Faculty of Medicine, Department of Pediatric Rheumatology, Ankara, Turkey

Background: Juvenile idiopathic arthritis (JIA) is a heterogeneous group of diseases characterized by unknown origin arthritis that begins before the age of 16 years (1). Therefore, families are often affected by the disease of children. Parents and children often disagree with assessing different aspects of disease activity in JIA (2).

Objectives: The aim of this study is to investigate the relationship between children with JIA and their parents' psychosocial status.

Methods: A total of 345 children with $\mathrm{JIA}$ and their parents were included in the study $(n=690)$. Juvenile Arthritis Biopsychosocial Questionnaire (JAB-Q) was administered to the subjects (3). The psychosocial status of the individuals was evaluated by this questionnaires.

Results: The mean age of children included in the study $(n=345)$ was $12.32 \pm 3.76$ years. While the median value of the Child Psychosocial score was 10 (min: 0 max: 38), the median value of the Parent Psychosocial score was 6 (min: 0 max: 20). Correlation coefficients and statistical significance were calculated by using the Pearson test. A positive low correlation was found between the psychosocial status of the child and parents $(r=0.273, p<0.001)$ (Table 1).

Table 1. Correlations

\begin{tabular}{|c|c|c|c|c|}
\hline \multirow{6}{*}{$\begin{array}{l}\text { JAB- } \\
Q\end{array}$} & \multirow{3}{*}{$\begin{array}{c}\text { Child } \\
\text { Psychosocial }\end{array}$} & $r$ & 1,00 & 0,283 \\
\hline & & $\bar{p}$ & & 0,000 \\
\hline & & $\mathrm{n}$ & 345 & 345 \\
\hline & \multirow{3}{*}{$\begin{array}{l}\text { Parents } \\
\text { Psychosocial }\end{array}$} & $r$ & 0,283 & 1,00 \\
\hline & & $\bar{p}$ & 0,000 & \\
\hline & & $\bar{n}$ & 345 & 345 \\
\hline
\end{tabular}

Conclusion: It was observed that there was a low relationship between the psychosocial status of children and parents. It was concluded that child and parents psychosocial status may be affected by other variables such as high disease activity, school attendance. Further studies are needed in this area including different variables and interaction psychosocial status.

\section{REFERENCES}

[1] Prakken, B., Albani, S., \& Martini, A. (2011). Juvenile idiopathic arthritis. The Lancet, 377(9783), 2138-2149.

[2] Garcia-Munitis P, Bandeira M, Pistorio A, Magni-Manzoni S, Ruperto N, Schivo A, et al. Level of agreement between children, parents, and physicians in rating pain intensity in juvenile idiopathic arthritis. Arthritis Rheum 2006;55:177-83.

Disclosure of Interests: None declared

DOI: 10.1136/annrheumdis-2019-eular.7319 AB1373-HPR

\section{AB1373-HPR BIOPSYCHOSOCIAL CHARACTERISTICS OF INPATIENTS, OUTPATIENTS AND PATIENTS WHO ATTEND A GROUP EXERCISE SESSIONS REGULARLY}

Yasemin Özel Aslıyüce, Aykut Özçadırcı' ${ }^{2}$, Gamze Arın ${ }^{3}$, Aybüke Seven ${ }^{3}$, Nur Banu Karaca ${ }^{4}$, Fatma Birgül Kumbaroğlu ${ }^{3}$, Edibe Ünal ${ }^{3}$, Şule Apraş Bilgen ${ }^{2}$. ${ }^{1}$ Institution of Health Sciences, Ankara, Turkey; ${ }^{2}$ Institution of Health Sciences, Ankara, Turkey; ${ }^{3}$ Institution of Health Science, Ankara, Turkey; ${ }^{4}$ Institution of Health Science, Ankara, Turkey

Background: Studies show that patients' biopsychosocial characteristics may be affected by various factors such as inpatient, outpatients, exercise intervention regularly. [1]. No studies have been found to examine this situation in the literature.
Objectives: The aim of this study was to investigate the biopsychosocial characteristics of patients with rheumatic diseases who were inpatients, outpatients and participated in an exercise intervention regularly.

Methods: A total of 105 patients were included in the study (inpatient, outpatient, exercise intervention) (Table 1). For exercise intervention group, BETY as a biopsychosocial exercise model was applied 3 days a week for 3 months [2]. Biopsychosocial characteristics of the patients included in the study were evaluated by BETY- Biopsychosocial Questionnaire (BETY-BQ) [3]. In addition to the total score of BETY-BQ, the same time pain, functionality and fatigue, sexuality, emotional status and socialization subcategory of this questionnaire were evaluated on item basis among each patients.

Results: The demographics variables and BETY-BQ scores of the patients were shown in Table 1. There were a statistically significant differences among three groups. After post-hoc analysis, it was determined that there is no difference between the BETY-BQ scores of the outpatients and inpatients $(p>0.05)$, whereas the BETY-BQ scores of the patients who participated in the group exercise were lower $(p 0.05)$. When the items were analyzed, it was found that pain (items $2,3,5$, and 12), functionality and fatigue (items $6,7,11,26$, and 28), emotional status (items 16 and 17), and sleep (item 30) subcategory scores were also lower in

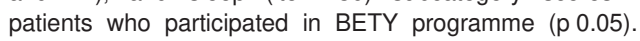

Abstract Table 1. Demographic statistics and BETY-BQ scores

\begin{tabular}{|c|c|c|c|c|c|c|c|}
\hline & & \multicolumn{2}{|c|}{$\begin{array}{c}\text { Inpatient } \\
(\mathrm{n}=30)\end{array}$} & \multicolumn{2}{|c|}{$\begin{array}{l}\text { Outpatıent } \\
\qquad(n=44)\end{array}$} & \multicolumn{2}{|c|}{$\begin{array}{c}\text { Exercise intervention } \\
\text { (BETY) } \\
(\mathrm{n}=\mathbf{3 1})\end{array}$} \\
\hline & & Female & Male & Female & Male & Female & Male \\
\hline \multirow[t]{2}{*}{ Gender (\%) } & & 61.3 & 37.8 & 87.2 & 12.8 & 53.7 & 7.4 \\
\hline & & \multicolumn{2}{|c|}{ XSD } & \multicolumn{2}{|c|}{ XSD } & \multicolumn{2}{|c|}{ XSD } \\
\hline Age (year) & & \multicolumn{2}{|c|}{46.3514 .56} & \multicolumn{2}{|c|}{46.0613 .26} & \multicolumn{2}{|c|}{48.6711 .89} \\
\hline BMI $\left(\mathrm{kg} / \mathrm{m}^{2}\right)$ & & \multicolumn{2}{|c|}{24.195 .17} & \multicolumn{2}{|c|}{28.9818 .85} & \multicolumn{2}{|c|}{26.943 .84} \\
\hline \multirow[t]{2}{*}{ BETY-BQ (0-120) } & $p$ & \multicolumn{2}{|c|}{ XSD } & \multicolumn{2}{|c|}{ XSD } & \multicolumn{2}{|c|}{ XSD } \\
\hline & 0.027 & \multicolumn{2}{|c|}{49.1017 .94} & \multicolumn{2}{|c|}{45.6427 .93} & \multicolumn{2}{|c|}{33.8121 .73} \\
\hline
\end{tabular}

Conclusion: It is surprising that the biopsychosocial characteristics of the inpatients and outpatients were similar. According to this result, inpatients shouldnt be thought as worse than outpatients. On the other hand, the patients who participated in exercise intervention were improved in terms of biopsychosocial aspects. The positive effects of the BETY program on the biopsychosocial status of individuals have been demonstrated formerly [4]. It was concluded that inpatients should be supported to exercise in terms of their biopsychosocial needs during hospitalization period as well as rheumatic outpatients need.

\section{REFERENCES}

[1] Saketkoo, L.A. and J.D. Pauling, Qualitative methods to advance care, diagnosis, and therapy in rheumatic diseases. Rheumatic Disease Clinics of North America, 2018.

[2] Kisacik, P., et al., Investigating the effects of a multidimensional exercise program on symptoms and antiinflammatory status in female patients with ankylosing spondylitis. Complement Ther Clin Pract, 2016. 22: p. 38-43.

[3] NAL, E., et al., Romatizmalı hastalar iin bir yaşam kalitesi leğinin geliştirilmesi: madde havuzunun olusturulması. Journal of Exercise Therapy and Rehabilitation, 2017. 4(2): p. 67-75.

[4] Unal, E., et al. Effectiveness of a Biopsychosocial Exercise Approach in Rheumatic Diseases. in ARTHRITIS \& RHEUMATOLOGY. 2018. WILEY 111 RIVER ST, HOBOKEN 07030-5774, NJ USA.

Disclosure of Interests: None declared

DOI: 10.1136/annrheumdis-2019-eular.7221

\section{AB1374-HPR THE EFFECTIVENESS OF BIOPSYCHOSOCIAL EXERCISE PROGRAM ON PAIN COPING IN PATIENTS WITH ANKYLOSING SPONDYLITIS AND FIBROMYALGIA}

Aybüke Seven ${ }^{1}$, Aykut Özçadırcl ${ }^{1}$, Gamze Arın ${ }^{1}$, Fatma Birgül Kumbaroğlu ${ }^{1}$, Nur Banu Karaca ${ }^{1}$, Ali Akdoğan ${ }^{2}$, Edibe Ünal ${ }^{1} .{ }^{1}$ Hacettepe University Faculty of Physical Therapy, Ankara, Turkey, ${ }^{2}$ Hacettepe University Faculty of Medicine, Department of Rheumatology, Ankara, Turkey

Background: Ankylosing spondylitis (AS) and fibromyalgia (FM) are rheumatic diseases with a high incidence in the community. Although many studies have been done on pain in these patient groups, the studies on coping with pain are very limited $(1,2)$. Bilişsel Egzersiz Terapi Yaklaşımı (BETY) is an exercise approach that developed in rheumatic patients. This approach has its own Biopsychosocial Questionnaire 